\title{
Hepatitis B and Delta Virus: Advances on Studies about Interactions between the Two Viruses and the Infected Hepatocyte
}

\author{
Katja Giersch ${ }^{1}$ and Maura Dandri*1,2 \\ ${ }^{1}$ Department of Internal Medicine, Center for Internal Medicine, University Medical Center Hamburg-Eppendorf, Hamburg, \\ Germany; ${ }^{2}$ German Center for Infection Research (DZIF), Hamburg-Lübeck-Borstel site, Germany
}

\begin{abstract}
The mechanisms determining persistence of hepatitis $B$ virus (HBV) infection and long-term pathogenesis of HBVassociated liver disease appear to be multifactorial. Although viral replication can be efficiently suppressed by the antiviral treatments currently available, viral clearance is generally not achieved since HBV has developed unique replication strategies, enabling persistence of its genome within the infected hepatocytes. Moreover, no direct antiviral therapy exists for the more than 15 million people worldwide that are also coinfected with the hepatitis delta virus (HDV), a defective virus that needs the HBV envelope proteins for propagation. The limited availability of robust HBV and HDV infection systems has hindered the understanding of the complex network of virus-virus and virushost interactions that are established in the course of infection and slowed down progress in drug development. Since chronic HBV/HDV coinfection leads to the most severe form of chronic viral hepatitis, elucidation of the molecular mechanisms regulating virus-host interplay and pathogenesis are urgently needed. This article summarizes the current knowledge regarding the interactions among HBV, HDV, and the infected target cell and discusses the dependence of HDV on HBV activity and possible future therapeutic approaches.

(C) 2015 The Second Affiliated Hospital of Chongqing Medical University. Published by XIA \& HE Publishing Ltd. All rights reserved.
\end{abstract}

Keywords: HBV; HDV; HBsAg; HDAg; Immune system; Hepatocytes; Virus interactions.

Abbreviations: ALT, alanine aminotransferase; $C H B$, chronic HBV; ER, endoplasmatic reticulum; $\mathrm{HBV}$, hepatitis $\mathrm{B}$ virus; $\mathrm{HBXAg}, \mathrm{HBV} X$ antigen; $\mathrm{HCC}$, hepatocellular carcinoma; HCV, hepatitis C virus; HDV, hepatitis delta virus; $\mathrm{HBCAg}$, hepatitis B core antigen; HBsAg, hepatitis B surface antigen; HDAg, hepatitis delta antigen; ISGs, interferon stimulated genes; $\mathrm{NF}_{\mathrm{KB}}$, nuclear factor kappa $\mathrm{B}$; NK, natural killer; NTCP, sodium taurocholate cotransporting polypeptide; NUCs, nucleoside/nucleotide analogues; pgRNA, pregenomic RNA; ROS, reactive oxygen species; SCID; severe combined immunodeficiency; SRE, serum response element; STAT, signal transducer and activator of transcription; TNF- $\alpha$, tumor necrosis factor alpha; USB mice, UPA/SCID/beige mice; UPA, urokinase-type plasminogen activator; WHO, World Health Organization.

Received: 21 May 2015; Revised: 11 July 2015; Accepted: 12 July 2015

DOI: $10.14218 / \mathrm{JCTH} .2015 .00018$.

*Correspondence to: Maura Dandri, Department of Internal Medicine, Center for Internal Medicine, University Medical Center Hamburg-Eppendorf, Martinistr. 52, D-20246 Hamburg, Germany. Tel: +49-40741052949, Fax: +49-40741057232, E-mail: m.dandri@uke.de
Hepatitis B virus

About 2 billion people worldwide have been in contact with the hepatitis $B$ virus (HBV), and according to the latest estimation of the World Health Organization (WHO), 240 million are chronically infected with HBV. Every year around 780,000 people die due to the consequences of HBV infection. ${ }^{1} \mathrm{HBV}$ belongs to the hepadnaviridae family and is a human-specific virus with a unique genome structure and replication cycle. ${ }^{2}$ Ten HBV genotypes have been described to date. Genotype A is prevalent in Africa and Northwestern Europe, while genotypes B and C are mainly found in Asia, Australia, and New Zealand. Genotype $D$ is predominant in Mediterranean countries, the Middle East, Central Asia, and India. Genotype $\mathrm{E}$ is restricted to West Africa, genotype $\mathrm{F}$ and $\mathrm{H}$ to Mexico and South America, and genotype $G$ to the United States and France. In the United States, genotypes A, B, C, D, and G have been found. ${ }^{3}$ Moreover, another genotype (I), was isolated in Vietnam ${ }^{4}$ and Laos $^{5}$ in 2008, and genotype J was identified in Japan in $2009 .^{6}$ However, due to the recent increase in the number of travelers and migrants, the original geographic distribution of the HBV genotypes cannot be applied as strictly anymore, and significant changes in the distribution will likely occur.

The circular HBV genome is approximately 3,200 base pairs (bp) long and exists in infecting virions (Dane particles) as a relaxed circular, partially double-stranded deoxyribonucleic acid (rcDNA). It is covalently linked to the terminal protein of the viral polymerase inside the nucleocapsid, which is formed by the hepatitis $\mathrm{B}$ core antigen ( $\mathrm{HBCAg}){ }^{7}$ The viral envelope encloses the nucleocapsid and consists of a lipid membrane and the hepatitis B surface antigens (HBsAg), which exist in three different forms: small, medium, and large. ${ }^{8}$ The sodium taurocholate cotransporting polypeptide (NTCP), a multiple transmembrane transporter localized to the basolateral membrane of highly differentiated primary hepatocytes, was identified as the bona fide receptor that permitted HBV and HDV entry into the hepatocytes. ${ }^{9}$ The entry pathway following HBV binding to the cell membrane has not been fully elucidated, but experimental evidence indicated that HBV was involved in an endocytosis process, followed by the release of the nucleocapsid from endocytic vesicles. Previous studies also indicated that the viral capsids were transported via microtubules to the nuclear periphery, ${ }^{10}$ where capsid accumulation would facilitate interactions with nuclear transport receptors and adaptor proteins of the nuclear pore complex. ${ }^{11}$ Within the nuclear baskets, 
disintegration of the capsids shall permit the release of both core capsid subunits and of the viral DNA polymerase complexes into the nucleoplasm. ${ }^{12}$ Although the mechanisms driving the formation of the covalently closed circular form (ccCDNA) remain largely unknown, the establishment of productive HBV infection requires the removal of the covalently attached viral polymerase and completion of the positivestrand by the cellular replicative machinery to form the supercoiled cccDNA molecule. This is then incorporated into the host chromatin and serves as the template of viral transcription and replication. ${ }^{13,14}$ Recent studies provided evidence that HBV used cellular DNA repair enzymes to remove the $P$ protein and initiate ccCDNA biogenesis. ${ }^{13,15,16}$ Using the cellular transcriptional machinery, the cccDNA serves as a stable template for the transcription of all viral ribonucleic acids (RNAs) necessary for protein production and replication of progeny viruses, which takes place in the cytoplasm after reverse transcription of an over-length pregenomic RNA (pgRNA). The stability of the cccDNA in hepatocyte nuclei plays a crucial role in the persistence of HBV infection. ${ }^{17}$ Other viral proteins, which are generated within the replication cycle of $\mathrm{HBV}$, are the $\mathrm{HBeAg}$ and the regulatory $\mathrm{X}$ protein. $\mathrm{HBeAg}$ is a nonstructural protein that is excreted from the infected hepatocyte into the blood and appears to act as a decoy for the immune system. ${ }^{2}$ The function of the HBV $X$ antigen (HBXAg) is not completely understood, but it has been shown to be essential for cccDNA transcription in vivo. ${ }^{18}$

The transmission of HBV occurs parenterally through infected blood or body fluids. In high endemic areas, HBV infection originates from transmission of an infected mother to her child during birth (perinatal transmission), while in low prevalence countries HBV is mainly transmitted through unprotected sexual contact and needle sharing among drug users. ${ }^{19}$ After an incubation time of 1 to 6 months, 2/3 of cases will have an acute HBV infection without symptoms (asymptomatic course), and $1 / 3$ of patients will develop unspecific symptoms, such as fatigue, weight-loss, anorexia, and nausea, and progress to disease with liver specific symptoms (jaundice and liver failure). Approximately $90 \%$ of acute infections in adults resolve spontaneously with the development of long-lasting immunity, ${ }^{20}$ while the remaining $10 \%$ develop a chronic HBV infection that over years is frequently associated with liver inflammation, leading to cirrhosis and increases in the incidence of hepatocellular carcinoma (HCC). ${ }^{21}$ Moreover, $90 \%$ of children infected before 1 year of age develop a chronic HBV infection. ${ }^{22}$ Approved therapeutic agents that decrease the morbidity and mortality of a chronic HBV infection are pegylated interferon- $\alpha$ and nucleoside/nucleotide analogues (NUCs). Although a seroconversion of HBeAg and serum HBV DNA levels below the lower limit of detection might be achieved with current therapeutics, a loss of HBsAg is rarely observed, and the complete eradication of the infection seems to be not possible.

Interferon- $\alpha$ acts both by modulating the immune system (through stimulation of interferon stimulated genes (ISGs) and modulation of natural killer (NK) cells) ${ }^{23-25}$ and by inducing direct antiviral effects, including epigenetic suppression of cccDNA transcription. ${ }^{26}$ NUCs (e.g. lamivudine, adefovir, and entecavir) inhibit the HBV polymerase ${ }^{27}$ but do not influence cccDNA-driven RNA transcription. Consequently, subgenomic RNAs coding for the envelope proteins, which are mostly secreted as subviral particles, are still produced, explaining why significant HBsAg reduction and seroconversion are rarely achieved with NUC-based treatments. ${ }^{28}$ Thus, novel therapies considering alternative antiviral targets and aiming to achieve a functional HBV cure are urgently needed. Among the new candidate drugs targeting steps of the viral life cycle distinct from HBV replication, Myrcludex- $B$, which is a myristoylated synthetic peptide binding NTCP and inhibiting viral attachment and entry, was shown to block efficiently the establishment of HBV infection and to hinder intrahepatic cccDNA accumulation in the spreading phase of infection both in vitro and in vivo, using humanized mice. ${ }^{29,30}$ The use of drugs efficiently protecting the hepatocytes from reinfection may represent an interesting therapeutic approach, since it could contribute to lower intrahepatic viral loads when used in combination with agents that aim to reduce not only HBV replication but to promote cccDNA destabilization and/or restoration of immune responses.

\section{Hepatitis Delta virus}

The hepatitis delta virus (HDV) was discovered in 1977 by Marcus Rizzetto. ${ }^{31}$ The outbreak, which started in Italy, has been brought under control in industrialized countries during the past 20 years. ${ }^{32,33}$ Nevertheless, still more than 15 million people worldwide are estimated to be chronically infected with $\mathrm{HDV}^{34}$ especially in developing continents like Asia and Africa where HDV infections remain a major health problem. ${ }^{35}$ Three major genotypes with highly variable sequences, which were further subdivided into eight HDV clades, have been reported. ${ }^{36}$ However, this classification was lately revised to group HDV subtypes into eight genotypes. ${ }^{37}$ With the exception of genotype 1 , which is the most frequent one and diffused worldwide, the other genotypes appear to be restricted to certain geographical areas: HDV-2 and 4 are mostly found in the Far East and Russia; HDV-3, which has been associated with the most severe form of chronic hepatitis, is mostly observed in the northern parts of South America in the Amazonian region; while genotypes $5,6,7$, and 8 are generally found in Africa or African migrants. ${ }^{38}$

The hepatitis delta virion is the smallest RNA pathogen known to interact with a human host and to cause substantial global morbidity and mortality. The inner nucleocapsid of the virus contains a 1,679 nucleotide long, single-stranded, circular RNA (genomic HDV RNA) and around 200 molecules of hepatitis delta antigen (HDAg), which is the only known protein encoded by the HDV RNA. Within the hepatocyte, replication leads to the accumulation of three HDV RNAs: the circular genomic RNA, the antigenomic RNA, and a smaller linear mRNA, which is the template for the translation of HDAg. HDV uses a so-called rolling cycle amplification mechanism and the host RNA polymerase II to transform the genomic HDV RNA into its exact complementary form, the antigenomic HDV RNA and then into new viral genomes. ${ }^{39,40}$ A unique open reading frame on the antigenomic HDV RNA leads to the synthesis of the HDAg, which occurs in two different forms: small HDAg and large HDAg. ${ }^{41}$ The small HDAg (24 kDa) is important for virus replication, whereas the large form (27 kDa) inhibits replication and leads to virion assembly. ${ }^{42,43}$ HDV is a defective virus, whose genome is surrounded by three HBV envelope proteins and host lipids (Fig. 1). ${ }^{44}$ HBV plays an essential role as a helper virus for HDV, since its envelope proteins are stringently necessary for HDV propagation. ${ }^{45}$ Therefore, the release of hepatitis delta virions from the infected hepatocytes can only occur if the 
Giersch K. et al: HBV/HDV interactions

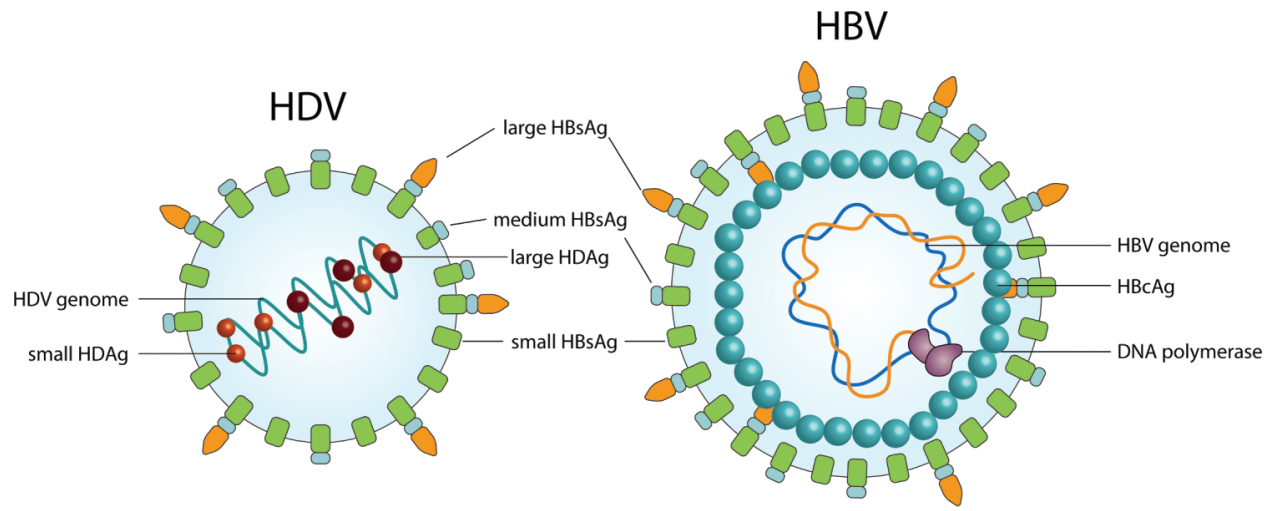

Fig. 1. HBV as a helper virus for HDV. Hepatitis B virus (HBV) shares its small, medium, and large hepatitis B surface antigens (HBsAg) with hepatitis D virus (HDV).

cells are coinfected with HBV or when HDV super-infection occurs in individuals already infected with HBV.

By sharing the same viral envelope (HBV viral proteins), HDV is also transmitted parenterally through infected blood or body fluids. Notably, HBV/HDV coinfections often cause more severe symptoms than HBV monoinfections. An acute coinfection emerges after an incubation time of 3 to 7 weeks and can either take an asymptomatic course, show several nonspecific symptoms (like fatigue, lethargy, anorexia, and nausea), or result in acute liver failure. ${ }^{46}$ In the setting of an HDV super-infection, up to $80 \%$ of the patients show a chronic course of disease, which is associated with liver inflammation, fibrosis, and decompensated liver cirrhosis. It is known that a super-infection with HDV and high HDV viremia levels increase the risk for a rapid progression to cirrhosis and HCC in comparison to an infection with HBV alone. ${ }^{39,47}$ In contrast, an HBV/HDV coinfection mostly occurs as an acute, self-limited infection and leads in less than $5 \%$ to a chronic manifestation. ${ }^{48}$ Since $\mathrm{HBV}$ vaccine is directed against the same envelope proteins that are used by HDV, vaccination against HBV also protects against HDV infections in individuals who are not already HBV-infected. Unfortunately, therapy options for HDV are very limited. There is no HDV-specific treatment, and currently the only approved drug is pegylated interferon- $\alpha$, which leads to unsatisfactory outcomes in HDV infected individuals. Different clinical trials revealed that sustained virological responses were achieved only in approximately $30 \%$ of HDV infected patients at the end of follow-up, ${ }^{49-51}$ demonstrating recrudescence of HDV after treatment discontinuation. Due to its simplicity in structure and lack of producing its own polymerase, HDV offers much fewer targets than other viruses and common HBV therapeutics cannot directly target HDV infection. Unfortunately, only a minority of patients treated with interferon clear HDV infection. Since HDV does not use a viral polymerase for replication, potent NUCs efficiently suppressing HBV reverse transcription do not show beneficial effects against HDV infection. ${ }^{52-54}$ Also ribavirin, which in combination with interferon was successfully used in chronic hepatitis $C$ virus (HCV) infections and was reported to have activity against HDV based upon in vitro studies, ${ }^{55}$ appeared ineffective for the treatment of HDV infected patients. ${ }^{56}$ Very few new therapeutic approaches exist. Myrcludex- $B$ is a promising entry inhibitor not only in HBV but also in HDV infections. ${ }^{57}$ An alternative to interferon- $\alpha$ might be treatment with interferon- $\lambda$, which appears to cause fewer side effects since its specific cellular receptor is restricted to cells of epithelial origin. ${ }^{58} \mathrm{~A}$ previous study revealed that prenylation of the large HDAg is essential for virus assembly and release and that prenylation inhibitors are able to decrease HDV RNA levels in vivo. ${ }^{59}$ Thus, the development of efficient therapeutic approaches, which directly target HDV replication, is urgently needed.

Interactions between HBV and HDV: in vitro, in vivo, and clinical studies

Since HDV requires the envelope proteins of HBV (HBsAg) for its assembly and release, a productive HDV infection, leading to the release of progeny viruses, exclusively occurs in the presence of HBV. It is thus plausible that both viruses have to interact with each other at different stages of their replication cycles. However, knowledge about the exact interplay between both viruses and to what extent HDV may influence HBV life cycle remains limited.

One of the first studies to address these questions was published in 1989, when direct inoculation of HDV genomes into the liver of an HBV infected chimpanzee showed transient $\mathrm{HBV}$ reduction during the acute phase of HDV infection. ${ }^{60}$ In 1990, Wu et al. cotransfected a human hepatoma cell line with plasmids coding for HBV and HDV genomes and found that HBV RNA transcriptional levels were dramatically suppressed in comparison to cells that were transfected with an HBV plasmid alone. Since a similar suppression of HBV RNAs (9- to 17-fold) and released HBV virions (9-fold) was also detected when these cells were cotransfected with an HBV plasmid and a plasmid expressing only the HDAg, Wu et al. concluded that the HBV RNA suppression must be mediated by the HDAg. ${ }^{61}$ Interestingly, the levels of genomic and antigenomic HDV RNA produced in vitro were not affected by the presence of $\mathrm{HBV}$, suggesting that $\mathrm{HBV}$ had no influence on HDV replication. ${ }^{61}$

Studies performed in mice harboring human livers (urokinase-type plasminogen activator (UPA)/severe combined immune deficiency (SCID)/beige mice (USB mice)) that were first stably infected with HBV and then superinfected with HDV, demonstrated a 0.6 log reduction of HBV viremia. In addition, the development of HBV viremia and intrahepatic cccDNA loads in humanized mice appeared to be delayed in the setting of HBV/HDV coinfection and in comparison to virological parameters obtained in HBV monoinfected 
animals. Taken together, these findings indicated that HDV may hinder HBV replication. ${ }^{57}$

The observation that HDV can suppress HBV in the setting of a co- or super-infection was also made in several retrospective patient studies. ${ }^{62-66}$ In 1991, Sagnelli et al. investigated 171 patients chronically infected with $\mathrm{HBV}$, who were HDAg-positive $(n=31)$, HDAg-negative but antiHDAg-positive $(n=54)$, or did not show any signs of present or past HDV infection $(n=86)$. Intrahepatic $\mathrm{HBcAg}$ was detected in $50 \%$ of the HBV monoinfected cohort, while only $6 \%$ of the HDAg-positive and $13 \%$ of the antiHDAg-positive patients had HBcAg-positive hepatocytes. ${ }^{66}$ Nevertheless, Colombo et al. described that hepatic inflammation was rather related to HBcAg levels in the liver of HBV infected individuals. Since such inflammation appeared to be independent of HDV superinfection, the study suggested that the levels of HBV replication, rather than HDV activity, might play a predominant role in causing liver damage among HBV/HDV infected individuals. ${ }^{63}$ However, controversial data exist about the ability of $\mathrm{HDV}$ to suppress $\mathrm{HCV}$ in the setting of $\mathrm{HBV} / \mathrm{HCV} / \mathrm{HDV}$ triple-infection. For instance, in a recent clinical study, Jardi et al. analyzed HBV/HDV coinfected, HBV/HCV/HDV tripleinfected, as well as HBV and HCV monoinfected individuals and found that HDV appeared to suppress both HBV and $\mathrm{HCV}$ viremia, though $\mathrm{HCV}$ replication was reduced to a greater extent than HBV. ${ }^{67}$ Moreover, Heidrich et al. investigated virological patterns in a cohort of 258 HDV infected patients from Central Europe and showed that HDV infection was associated with suppression of both HBV and HCV replication. ${ }^{68}$ In contrast, HBV DNA and HCV RNA levels did not seem to influence HDV replication in that patient cohort, and mean HBsAg levels did not significantly differ between HBV monoinfected and HBV/HDV coinfected patients. ${ }^{68}$ While Eyster et al. and Mathurin et al. also supported the observation that HDV predominated HCV in triple-infected patients by failing to detect serum HCV RNA and markers of HBV replication in most of the patients, ${ }^{69,70}$ Liaw et al. showed that HCV is the dominant virus in triple infected patients in Asia. ${ }^{71}$ Since these studies were conducted in different patient populations, the discrepancies suggested that patient polymorphisms, viral genotype varieties, as well as environmental factors add complexity and have to be taken into account, since all these factors may strongly influence virus-virus interactions and the clinical outcome of the infection. Although infection with HDV is frequently associated with a more severe disease course compared to other hepatitis virus infections, different HDV genotypes have been associated with different clinical manifestations. For example, HDV genotype 3 is considered to cause a more fulminant hepatitis than genotypes 2 and 4, while patients infected with HDV genotype 1 can develop a wide range of severity. ${ }^{72}$ Clini$\mathrm{cal}^{73,74}$ and in vitro observations ${ }^{75}$ demonstrated that various combinations with different HBV genotypes are possible and that some HBV strains seem to favor HDV assembly and improve HDV infectivity ${ }_{i}^{75}$ factors that might also influence clinical manifestations. In contrast, Shih et al. did not find a positive correlation between replication and assembly capacities of HDV in relation to distinct HBV genotypes, thus questioning the impact of different HBV genotypes on clinical outcomes of HDV infections. ${ }^{76}$

To investigate the interplay of HBV and HDV during the course of coinfection, an interesting longitudinal study was published by Schaper et al. in 2010, where HBV and HDV replicative activities were evaluated for up to 8 years in 25 chronically HBV/HDV coinfected patients. ${ }^{77}$ Interestingly, seven different replication profiles were observed in these patients. $20 \%$ of the coinfected individuals showed a persistent activity of HDV in the absence of HBV activity; $12 \%$ demonstrated a persistent activity of both viruses, while another $12 \%$ showed persistent HBV activity in the absence of HDV replication. The remaining $56 \%$ of patients showed a fluctuating activity of both viruses (24\%) or of one of the two viruses (32\%). HDV was dominant in most of the patients observed $(60 \%)$, but a predominance of HBV $(16 \%)$ or none of the two viruses was also determined in a remarkable number of coinfected individuals $(24 \%) .{ }^{77}$

What we should learn from the results obtained from these different cross-sectional and longitudinal clinical studies is that HDV seemed to be able to suppress HBV and HCV at certain time points in the course of concomitant infection. Since multiple virological and host-related events (i.e. viral genotypes, immune state, and environmental factors) may affect viremia levels, HDV cannot generally and necessarily be considered the predominant virus in all HBV/HDV coinfected patients based on a single determination. ${ }^{78}$

\section{Interactions between HBV and HDV: role of the HBsAg}

During the replication cycle of HDV, the surface proteins of HBV specifically interact with the HDAg at the endoplasmic reticulum (ER) of the infected cells and, hence, are essential for HDV assembly. ${ }^{79}$ The detection of HBsAg in serum is not only a fundamental diagnostic marker of HBV infection, but it may also be a promising prognostic marker during the natural history of chronic HBV infection and antiviral therapy. ${ }^{80}$ The natural history of chronic HBV (CHB), in general, is regarded to consist of four phases: immune tolerant phase, $\mathrm{HBeAg}-$ positive chronic hepatitis (immune clearance), immune control (with low or nonreplicative HBV), and HBeAg negative hepatitis (immune escape). These phases have been identified on the basis of specific biochemical, serological, and virological characteristics, including serum alanine aminotransferase (ALT) levels, $\mathrm{HBeAg}$ status, viremia, and $\mathrm{HBsAg}$ levels. ${ }^{81}$ In the acute and early stages of $\mathrm{CHB}$ monoinfection (immune tolerant phase), HBsAg often correlates with serum HBV DNA levels in infected patients. ${ }^{82}$ Moreover, HBsAg levels can vary among HBV genotypes as well as fluctuate over the years. ${ }^{83,84}$ Jaroszewicz et al. investigated 226 HBV monoinfected individuals at different phases of chronic infection and detected no or weak correlations between HBsAg and viremia, indicating that HBsAg production and HBV DNA replication can differ at later time points of $\mathrm{CHB}$ (i.e. during immune clearance and control). ${ }^{80}$ This could be due to the accumulation of HBV DNA integrations that may provide a separate template for $\mathrm{HBsAg}$ production, the emergence of variants (where $\mathrm{HBeAg-negative} \mathrm{variants} \mathrm{are} \mathrm{the} \mathrm{most} \mathrm{fre-}$ quently found), or immune-mediated factors, including cytokines, which affect cccDNA transcription. ${ }^{78}$ On the other hand, Volz et al. found that serum HBsAg levels were significantly lower in $\mathrm{HBeAg}$-negative individuals and that lower intrahepatic cccDNA levels correlated with lower HBsAg concentrations in serum. ${ }^{83}$

Cross-sectional studies showed in HBV/HDV coinfections that HBsAg levels were usually high, despite lower levels of HBV viremia. ${ }^{85}$ Moreover, Shih et al. found a positive correlation between HDV productivity and expression levels of HBsAg but not with HBV DNA levels or HBV genotypes. ${ }^{76}$ In contrast, a longitudinal study performed by Schaper et al. 
demonstrated that levels of circulating HBsAg in HBV/HDV coinfected patients showed significant fluctuating profiles, suggesting that HDV may be directly responsible for the HBsAg flares. ${ }^{77}$ However, contrary to the earlier cross-sectional studies, this study failed to detect a positive correlation between HBsAg levels and amounts of HDV RNA. ${ }^{77}$ It should be noted that these clinical observations are not supported by experimental evidence, and a complex interplay of virological and host factors may be involved. At present, it can be only hypothesized that HBV viremia and HBsAg fluctuations reflect in part a specific suppression of the HBV replication pathway, which could occur, for instance, by sequestering the envelope proteins needed for HBV release or by differentially affecting distinct HBV promoters. Future studies using well controlled experimental systems will be needed to address these hypotheses.

Infectious HDV particles can enter and replicate within a hepatocyte in the absence of HBV, since these steps only need the presence of host factors and enzymes. ${ }^{86}$ The coexistence of both viruses, and in particular the HBV envelope proteins, in the same hepatocyte is necessary for HDV packaging and release. ${ }^{87}$ Recently, several studies have attempted to reveal at a molecular level the role of HBsAg in HDV infection. While the large envelope protein has been shown to bind specifically to the cellular receptor NTCP ${ }^{9}$ and, thus, be essential for HBV and HDV infectivity, ${ }^{72,88}$ the presence of the small envelope protein appears to be sufficient for HDV packaging and release. ${ }^{87}$

The HDAgs are predominant in the nucleus of the infected hepatocyte ${ }^{89}$ but can be post-translationally modified (e.g. acetylation, isoprenylation, and phosphorylation). ${ }^{90}$ Isoprenylation of the large HDAg was shown to lead to its translocation to the $\mathrm{ER}_{1}{ }^{91}$ where it promoted HDV assembly by directly interacting with the small HBsAg (Table 1). ${ }^{92,93}$ Changes in certain tryptophan-rich motifs in the carboxyl terminus of the small envelope protein of $\mathrm{HBV}^{79}$ and within other distinct $\mathrm{HBV}$ envelope protein regions ${ }^{92}$ were shown to affect such proteinprotein interactions and negatively influence the assembly capacities of HDV. Hence, the emergence of HBV and/or HDV variants may also explain the fluctuating activities of HDV observed in the longitudinal study by Schaper et al. ${ }^{77}$

Huang et al. suggested that accumulation in the ER of all three HBV envelope proteins, especially of the large HBsAg, may increase the translocation of the large HDAg from the nucleus to the ER. This process, however, not only mediated HDV packaging but also caused ER stress. ${ }^{94}$ Treatment of human hepatoma cells with two different ER stress inducers, brefeldin A and tunicamycin, was shown to promote the translocation of the large HDAg in the absence of HBsAg, at least in some cells $(9 \%)$. During the same in vitro experiments, the HBsAg-induced translocation of the large HDAg was accompanied by an increase in nuclear nuclear factor kappa $B$ (NFKB) activity, while inhibition of nuclear NFKB was shown to retain the large HDAg in the nucleus. In agreement with these observations, $\mathrm{NF}_{\kappa} \mathrm{B}$ activation induced by tumor necrosis factor alpha (TNF- $\alpha$ ) strongly promoted HDAg translocation in $50 \%$ of the cells, suggesting that ER stress and $\mathrm{NF} \kappa \mathrm{B}$ play an import role in the interaction of HBV and HDV during the stage of HDV assembly (Table 1 ). ${ }^{94}$

Table 1. Interaction between HBV, HDV, and the infected target cell

\begin{tabular}{|c|c|c|}
\hline Interaction & Effect & Reference \\
\hline \multicolumn{3}{|c|}{ HDV-HBV interaction } \\
\hline L-HDAg $\leftrightarrow \mathrm{S}-\mathrm{HBsAg}$ & HDV assembly & 92,93 \\
\hline S/L-HDAg $\leftrightarrow$ HBV enhancers Enh1/2 & HBV suppression & 97 \\
\hline \multicolumn{3}{|c|}{ HDV-interaction with host factors } \\
\hline L-HDAg $\leftrightarrow$ DNA dependent RNA-polymerase II & HBV suppression & 96 \\
\hline L-HDAg $\leftrightarrow$ genes of SRE-dependent pathway & HBV suppression & 95 \\
\hline S/L-HDAg $\leftrightarrow$ MxA & $\begin{array}{l}\text { Induction innate immune responses, } \\
\text { HBV suppression }\end{array}$ & 97 \\
\hline HDV $\leftrightarrow$ ISGs, signaling genes, cytokines & $\begin{array}{l}\text { Induction innate immune responses, } \\
\text { HBV suppression }\end{array}$ & 107 \\
\hline \multicolumn{3}{|c|}{ HBV-interaction with host factors } \\
\hline $\mathrm{HBsAg} \leftrightarrow \mathrm{NF} \kappa \mathrm{B}, \mathrm{TNF}-\alpha$, ER-stress pathway & $\begin{array}{l}\text { Translocation of HDV from nucleus to } \\
\text { ER, HDV assembly }\end{array}$ & 94 \\
\hline HBsAg $\leftrightarrow$ TLR signaling & Suppression TLR signaling & 110,111 \\
\hline $\mathrm{HBeAg} \leftrightarrow \mathrm{TLR} 2$ & $\begin{array}{l}\text { Impairment innate immune } \\
\text { responses }\end{array}$ & 109 \\
\hline HBV $\leftrightarrow$ cellular DNA methyltransferases & Epigenetic modifications & 115,116 \\
\hline HBx protein $\leftrightarrow$ innate signaling pathways & $\begin{array}{l}\text { Impairment innate immune } \\
\text { responses }\end{array}$ & 117 \\
\hline $\mathrm{HBV} \leftrightarrow \mathrm{STAT}$ translocation & Impairment IFN signaling & 112,113 \\
\hline
\end{tabular}




\section{Interactions between HBV and HDV: role of the HDAg}

Small and large HDAgs are not only involved in HDV replication and packaging, respectively, but they also appear to interact with $\mathrm{HBsAg}$ on an indirect molecular level, whereby they may be able to influence $\mathrm{HBV}$ replication. ${ }^{95-97}$

The large HDAg is known to be involved in HDV packaging by directly binding HBV surface proteins through its hydrophobic packaging signal ${ }^{98}$ and its hydrophobic farnesylated C-terminal domain, ${ }^{99}$ while the small HDAg binds to the HDV RNA and promotes HDV replication. An in vitro study by Wang et al. suggested that this HDAg-HDV RNA ribonucleoprotein complex also enhanced efficacy of HDV assembly, probably because the interaction between the large HDAg and HDV RNA was increased in the presence of the small HDAg (due to additional binding sites). ${ }^{43}$ Indirect molecular interactions between $\mathrm{HDAg}$ and $\mathrm{HBV}$ were described by Modahl et al. in 2000, who suggested that the suppressive effect of HDV on HBV replication could be mediated by the large HDAg, which might inhibit not only the replication of HDV but also the transcription of the cccDNA by interacting with the host DNA-dependant RNA polymerase II. $^{96}$ Investigation of the interplay between HBV and HDV in a hepatoma cell line cotransfection model suggested that both the small and large HDAg were able to repress the two HBV enhancers, termed Enh1 and Enh2. ${ }^{97}$ Of note, the same study also indicated that the large HDAg can activate the MxA promoter, thereby potentiating the effect of interferon- $\alpha$ on this cellular promoter. Moreover, the same study also suggested that HBV replication may be then inhibited by the antiviral activity of the interferon- $\alpha$ inducible MxA protein. ${ }^{97}$ Goto et al. showed that the HBxAg and the large HDAg can synergistically activate the serum response element (SRE)-dependent pathway, which is involved in the expression of various genes that regulate cell growth, differentiation, and transformation. The synergistic induction of pathways involved in carcinogenesis $^{95}$ could in part explain the more severe course of HDV associated liver disease and why HBV/HDV coinfected patients developing primary HCC are usually younger than HBV monoinfected individuals. ${ }^{100}$ Also Wei and Ganem used an in vitro approach to show that the large, but not the small HDAg, has the capacity to activate heterologous gene expression by acting on a variety of promoters, including the pre-S, S, and C promoters of HBV. ${ }^{101}$

In summary, several possible interactions between HBV and HDV have been highlighted (Table 1). Many in vitro and in vivo studies, as well as clinical observations, have indicated that HDV is able to suppress the replication of HBV at certain time points of the coinfection. In this regard, the large HDAg seems to play a major role in mediating HBV suppression. Moreover, the fact that HBV surface antigens can mediate and increase HDV assembly ${ }^{92,93}$ demonstrates the dependence of HDV on HBV as its helper virus and underscores the necessity of HDV to maintain HBV surface protein productivity. Although different interacting mechanisms have been suggested, further studies are needed to understand the impact of specific virus-virus interactions in the course of chronic infection, while a better understanding of the complex HBV/HDV interplay might even help identify new therapeutic strategies to cure chronic HBV and HDV infections.

\section{Interactions between HBV/HDV and human} hepatocytes

Because there are only a few models available to study chronic infections with HBV and HDV in human hepatocytes, and biopsies of infected patients are rarely available, knowledge about interactions between HBV and HDV and the infected hepatocytes is scant.

While HBV is regarded as a virus that under most conditions is not directly cytopathic to infected hepatocytes, data from chimpanzees and specific clinical cases suggested direct cytopathic effects of HDV on hepatocytes, ${ }^{102-104}$ particularly in the acute hepatitis setting. ${ }^{105}$ In comparison to HBV, HDV generally shows a more severe clinical course. Experimental studies in chimpanzees, ${ }^{106}$ humanized mice, ${ }^{107}$ and recent patient observations ${ }^{108}$ have indicated that HBV does not induce a strong activation of the innate immune system or interferon stimulated genes (ISGs) in the acute and chronic status of infection.

Moreover, different lines of evidence indicated that HBV was able to circumvent the induction of immune responses of the host by several mechanisms. ${ }^{2}$ Both experimental studies ${ }^{109}$ and observations in chronic HBV infected patients ${ }^{110,111}$ indicated that the activation of toll-like receptor signaling molecules is impaired, while studies in vitro ${ }^{112}$ and in human liver chimeric mice showed ${ }^{113}$ that HBV can limit the interferon alpha mediated nuclear translocation of signal transducer and activator of transcription (STAT) (Table 1). In vitro studies also reported that HBV can interfere with STAT methylation ${ }^{114}$ and activity of cellular DNA methyltransferases, ${ }^{115,116}$ while HBV proteins, such as HBx protein, were shown to affect innate immunity pathways by downregulating mitochondrial antiviral signaling proteins (Table 1 ). ${ }^{117}$

In humanized mice, establishment of a stable HBV/HDV coinfection was shown to provoke a significant and sustained enhancement of the innate defense mechanisms in human hepatocytes compared to HBV infected animals. ${ }^{107}$ Classic human ISGs and broadly acting effectors of the innate antiviral responses, such as Rig-I as well as STAT transcription factors, which are key signaling molecules that can be activated through direct viral actions ${ }^{118}$ were significantly higher in the setting of a chronic HDV infection. ${ }^{107}$ Also, the expression of genes involved in antigen presentation and in recognition of infected cells by NK cells (e.g. hHLA-E, and hTAP1) was significantly increased compared to uninfected and HBV monoinfected mice. ${ }^{107}$ This strong antiviral state caused by HDV observed in this study could also affect HBV replication in coinfected livers (Table 1) and, hence, may in part explain the lower levels of HBV infection, which were frequently found in experimental approaches and in HBV/HDV coinfected patients. ${ }^{62-66}$

\section{Interactions between HBV/HDV and the immune} system of the host

HBV persistence is also associated with defective $T$ cell responses characterized by suppression, dysfunction, and exhaustion of HBV-specific T cells, which appears to be provoked by dysregulation of costimulatory pathways, impairment of $\mathrm{T}$ cell receptor signaling, and enhanced $\mathrm{T}$ cell apoptosis. ${ }^{119}$ However, HDV infected patients advance more rapidly in their disease than patients infected with HBV or $\mathrm{HCV}^{34}$ and clinical observations indicated that the liver damage associated with chronic HDV infection and the 
severe course of infection seemed mainly to be immunemediated. The small HDAg is thought to be responsible for the direct cytopathic effect on human hepatocytes, while the large HDAg seems to be noncytotoxic but promotes the persistence of HDV and may make hepatocytes susceptible to immune-mediated damage. ${ }^{39,102}$ Although both innate and adaptive immune responses are believed to contribute to the pathogenesis of an HDV infection, detailed host immune responses in HDV infection are poorly investigated to date. ${ }^{39}$ One very early study suggested that NK cells were activated upon interferon treatment in HDV infected individuals. ${ }^{120}$ A more recent analysis in HDV infected patients revealed elevated levels of peripheral blood NK cells with a reduced functional capacity in their ability to respond to interferon- $\alpha$ treatment compared to healthy donors. A high frequency of NK cells before and during interferon treatment was positively associated with treatment outcome. ${ }^{121}$ Moreover, in vitro experiments showed that the large HDAg might be able to activate STAT3 and NF-кB signaling ${ }^{97,122}$ and that HDV interfered with interferon- $\alpha$ signaling by blocking the activation and translocation of STAT proteins, thereby contributing to the persistence of HDV and impairing therapy outcomes. ${ }^{123}$ It was also suggested that this activation of STAT3 and NF- $\mathrm{KB}$ signaling by the large HDAg not only caused ER stress and necroinflammation but also increased the production of reactive oxygen species (ROS), possibly leading to the development of HCC. ${ }^{39}$ In this regard, HDAg-induced STAT3 seemed to be able to activate DNA methyltransferases, which are known to silence tumor suppressor genes and lead to the development of HCC. Furthermore, HCC is often associated with an overexpression of clusterin. Interestingly, the large HDAg was shown to increase histone $\mathrm{H} 3$ acetylation of clusterin promoters and cell survival potential. ${ }^{39}$

Adaptive immune responses in HDV infections are, in general, weak. ${ }^{121}$ In chronic HDV infected patients, responses of helper $\mathrm{T}$ cells are associated with a high frequency of secreting interleukin-10, which has immunomodulatory effects and inhibits interferon pathways. ${ }^{124}$ In addition, perforin-positive cytotoxic CD4+ T cells, which are linked with killing infected cells, accumulated in chronically infected patients, and this might explain the more severe course of HDV associated liver diseases. ${ }^{125}$ CD8+ T cell responses seemed to be weaker and were only detected in patients with past, but not active, HDV infections. ${ }^{126}$ Impaired T cell responses observed in the setting of a chronic HBV/HDV coinfection occurred possibly due to the presence of HBV and its association with defective T cells responses. Since the activation of immune cells appeared to be limited in chronically HDV infected patients, it seems plausible that HDV exerts most of its effects in the liver itself, where the virus can mediate intracellular changes and can initiate inflammatory pathways.

\section{Conclusions}

The fluctuating virus profiles observed in HBV/HDV coinfected patients clearly show that the course of infection can be highly dynamic. Moreover, in vitro and in vivo experiments indicated that HDV is able to suppress HBV and even HCV replication. ${ }^{57,61-70}$ As a consequence, HDV often appears as the predominant virus in coinfected individuals. ${ }^{77}$ In this regard, in vitro studies indicated that both the small and large HDAg proteins can be responsible for the reduction of HBV activity, since interactions of these proteins with host polymerases and HBV enhancers, as well as the induction of antiviral
ISGs and genes involved in cell growth and differentiation, have been described. ${ }^{95-97}$ In vivo HBV/HDV coinfection of human hepatocytes was also shown to upregulate antiviral ISGs, signal molecules of innate immune response cascades, and cytokines more greatly than HBV alone. ${ }^{107}$ Such proinflammatory status may explain the more severe course of disease in HDV infected patients. Since HBV acts as a helper virus by supplying its envelope proteins to HDV, productive HDV infections are strongly dependent on the expression of HBV envelope proteins. It is thus not surprising that, at least in certain phases of the infection, the levels of circulating HBsAg correlate with HDV RNA levels. ${ }^{76,77}$ In vitro studies also proposed that HBsAg promotes nuclear export of the large HDAg and HDV assembly by inducing ER stress, nuclear $N F \kappa B$ translocation, and TNF- $\alpha$ production; thus pointing out the existence of complex cross-talk among HBV, HDV, and the infected cell. ${ }^{72,94}$ Cell-mediated prenylation of the large HDAg is also important for the efficient translocation and assembly of HDV. ${ }^{91-93}$ Since this step appears to be crucial in the HDV life cycle, prenylation inhibitors, such as lonafarnib, are currently being tested in clinical studies. The use of HBsAg inhibitors may also represent an interesting approach for targeting HDV assembly, since a strong decrease of HBsAg levels is expected to affect the amounts of circulating delta virions.

The availability of innovative experimental systems and techniques, which allow for more sensitive molecular analyses of these viruses and of the host, has begun to provide new insight into the complex network of virus-host interactions that are established in the course of viral hepatitis infection and therapy. Nevertheless, because of the limitations encountered by using any experimental model, studies based on human blood and liver biopsy samples remain indispensable to gain insights about the pathobiology of HBV and HBV/HDV infection and for the development of effective HBV/HDV therapies that will permit achievement of a functional HBV cure and HDV eradication.

\section{Conflict of interest}

None

\section{Author contributions}

Writing the manuscript and designing the figure and table (KG, MD).

\section{References}

[1] Lozano R, Naghavi M, Foreman K, Lim S, Shibuya K, Aboyans V, et al. Global and regional mortality from 235 causes of death for 20 age groups in 1990 and 2010: a systematic analysis for the Global Burden of Disease Study 2010. Lancet 2012;380:2095-2128. doi: 10.1016/S0140-6736(12) 61728-0.

[2] Dandri M, Locarnini S. New insight in the pathobiology of hepatitis B virus infection. Gut 2012;61:i6-i17. doi: 10.1136/gutjnl-2012-302056.

[3] Kao JH. Hepatitis B viral genotypes: clinical relevance and molecular characteristics. J Gastroenterol Hepatol 2002;17:643-650. doi: 10.1046/j. 1440-1746.2002.02737.x.

[4] Tran TT, Trinh TN, Abe K. New complex recombinant genotype of hepatitis B virus identified in Vietnam. J Virol 2008;82:5657-5663. doi: 10.1128/JVI. 02556-07.

[5] Olinger CM, Jutavijittum P, Hubschen JM, Yousukh A, Samountry B, Thammavong $T$, et al. Possible new hepatitis $B$ virus genotype, southeast Asia. Emerg Infect Dis 2008;14:1777-1780. doi: 10.3201/eid1411.080437.

[6] Tatematsu K, Tanaka Y, Kurbanov F, Sugauchi F, Mano S, Maeshiro T, et al. A genetic variant of hepatitis $B$ virus divergent from known human and ape 
genotypes isolated from a Japanese patient and provisionally assigned to new genotype J. J Virol 2009;83:10538-10547. doi: 10.1128/JVI.00462-09.

[7] Delius H, Gough NM, Cameron CH, Murray K. Structure of the hepatitis B virus genome. J Virol 1983;47:337-343.

[8] Bruss V. Envelopment of the hepatitis B virus nucleocapsid. Virus Res 2004; 106:199-209. doi: 10.1016/j.virusres.2004.08.016.

[9] Yan H, Zhong G, Xu G, He W, Jing Z, Gao Z, et al. Sodium taurocholate cotransporting polypeptide is a functional receptor for human hepatitis $\mathrm{B}$ and D virus. Elife 2012;1:e00049. doi: 10.7554/eLife.00049.

[10] Rabe B, Glebe D, Kann M. Lipid-mediated introduction of hepatitis B virus capsids into nonsusceptible cells allows highly efficient replication and facilitates the study of early infection events. J Virol 2006;80:5465-5473. doi: 10.1128/JVI.02303-05.

[11] Kann M, Schmitz A, Rabe B. Intracellular transport of hepatitis B virus. World J Gastroenterol 2007;13:39-47. doi: 10.3748/wjg.v13.i1.39.

[12] Schmitz A, Schwarz A, Foss M, Zhou L, Rabe B, Hoellenriegel J, et al. Nucleoporin 153 arrests the nuclear import of hepatitis $B$ virus capsids in the nuclear basket. PLoS Pathog 2010;6:e1000741. doi: 10.1371/journal.ppat. 1000741.

[13] Nassal M. Hepatitis B viruses: reverse transcription a different way. Virus Res 2008;134:235-249. doi: 10.1016/j.virusres.2007.12.024.

[14] Newbold JE, Xin H, Tencza M, Sherman G, Dean J, Bowden S, et al. The covalently closed duplex form of the hepadnavirus genome exists in situ as a heterogeneous population of viral minichromosomes. J Virol 1995; 69:3350-3357.

[15] Bock CT, Schwinn S, Locarnini S, Fyfe J, Manns MP, Trautwein C, et al. Structural organization of the hepatitis B virus minichromosome. J Mol Biol 2001;307:183-196. doi: 10.1006/jmbi.2000.4481.

[16] Koniger C, Wingert I, Marsmann M, Rosler C, Beck J, Nassal M. Involvement of the host DNA-repair enzyme TDP2 in formation of the covalently closed circular DNA persistence reservoir of hepatitis B viruses. Proc Natl Acad Sci U S A 2014;111:E4244-E4253. doi: 10.1073/pnas.1409986111.

[17] Levrero M, Pollicino T, Petersen J, Belloni L, Raimondo G, Dandri M. Control of cccDNA function in hepatitis B virus infection. J Hepatol 2009;51:581-592. doi: 10.1016/j.jhep.2009.05.022.

[18] Lucifora J, Arzberger S, Durantel D, Belloni L, Strubin M, Levrero M, et al. Hepatitis $B$ virus $X$ protein is essential to initiate and maintain virus replication after infection. J Hepatol 2011;55:996-1003. doi: 10.1016/j.jhep. 2011.02.015.

[19] Shepard CW, Simard EP, Finelli L, Fiore AE, Bell BP. Hepatitis B virus infection: epidemiology and vaccination. Epidemiol Rev 2006;28:112125. doi: 10.1093/epirev/mxj009.

[20] Shiffman ML. Management of acute hepatitis B. Clin Liver Dis 2010;14: 75-91; viii-ix. doi: 10.1016/j.cld.2009.11.013.

[21] Bertoletti A, Gehring A. Immune response and tolerance during chronic hepatitis B virus infection. Hepatol Res 2007;37:S331-S338. doi: 10.1111/j. 1872-034X.2007.00221.x.

[22] Chang $\mathrm{MH}$. Natural history and clinical management of chronic hepatitis $B$ virus infection in children. Hepatol Int 2008;2:28-36. doi: 10.1007/s12072008-9050-9.

[23] Kakimi K, Guidotti LG, Koezuka Y, Chisari FV. Natural killer T cell activation inhibits hepatitis B virus replication in vivo. J Exp Med 2000;192:921-930. doi: 10.1084/jem.192.7.921.

[24] Randall RE, Goodbourn S. Interferons and viruses: an interplay between induction, signalling, antiviral responses and virus countermeasures. J Gen Virol 2008;89:1-47. doi: 10.1099/vir.0.83391-0.

[25] Stegmann KA, Bjorkstrom NK, Veber H, Ciesek S, Riese P, Wiegand J, et al. Interferon-alpha-induced TRAIL on natural killer cells is associated with control of hepatitis C virus infection. Gastroenterology 2010;138:18851897. doi: $10.1053 /$ j.gastro.2010.01.051.

[26] Belloni L, Allweiss L, Guerrieri F, Pediconi N, Volz T, Pollicino T, et al. IFN-alpha inhibits HBV transcription and replication in cell culture and in humanized mice by targeting the epigenetic regulation of the nuclear ccCDNA minichromosome. J Clin Invest 2012;122:529-537. doi: 10.1172/ JCI58847.

[27] Grimm D, Thimme R, Blum HE. HBV life cycle and novel drug targets. Hepatol Int 2011;5:644-653. doi: 10.1007/s12072-011-9261-3.

[28] Petersen J, Dandri M. Optimal therapy for chronic hepatitis B: hepatitis B virus combination therapy? Liver Int 2015;35:114-120. doi: 10.1111/liv. 12720.

[29] Petersen J, Dandri M, Mier W, Lutgehetmann M, Volz T, von Weizsacker F, et al. Prevention of hepatitis $B$ virus infection in vivo by entry inhibitors derived from the large envelope protein. Nat Biotechnol 2008;26: 335-341. doi: 10.1038/nbt1389.

[30] Volz T, Allweiss L, Ben MM, Warlich M, Lohse AW, Pollok JM, et al. The entry inhibitor Myrcludex-B efficiently blocks intrahepatic virus spreading in humanized mice previously infected with hepatitis B virus. J Hepatol 2013;58:861-867. doi: 10.1016/j.jhep.2012.12.008.

[31] Rizzetto M, Canese MG, Arico S, Crivelli O, Trepo C, Bonino F, et al. Immunofluorescence detection of new antigen-antibody system (delta/anti- delta) associated to hepatitis B virus in liver and in serum of $\mathrm{HBsAg}$ carriers. Gut 1977;18:997-1003.

[32] Gaeta GB, Stroffolini T, Chiaramonte M, Ascione T, Stornaiuolo G, Lobello S, et al. Chronic hepatitis D: a vanishing Disease? An Italian multicenter study. Hepatology 2000;32:824-827. doi: 10.1053/jhep.2000.17711.

[33] Navascues CA, Rodriguez M, Sotorrio NG, Sala P, Linares A, Suarez A, et al. Epidemiology of hepatitis $D$ virus infection: changes in the last 14 years. Am J Gastroenterol 1995;90:1981-1984.

[34] Hughes SA, Wedemeyer H, Harrison PM. Hepatitis delta virus. Lancet 2011; 378:73-85. doi: 10.1016/S0140-6736(10)61931-9.

[35] Ciancio A, Rizzetto M. Chronic hepatitis D at a standstill: where do we go from here? Nat Rev Gastroenterol Hepatol 2014;11:68-71. doi: 10. 1038/nrgastro.2013.164.

[36] Le Gal F, Gault E, Ripault MP, Serpaggi J, Trinchet JC, Gordien E, et al. Eighth major clade for hepatitis delta virus. Emerg Infect Dis 2006;12:1447-1450. doi: 10.3201/eid1209.060112.

[37] Alvarado-Mora MV, Locarnini S, Rizzetto M, Pinho JR. An update on HDV: virology, pathogenesis and treatment. Antivir Ther 2013;18:541-548. doi: 10.3851/IMP2598.

[38] Deny P. Hepatitis delta virus genetic variability: from genotypes I, II, III to eight major clades? Curr Top Microbiol Immunol 2006;307:151-171.

[39] Abbas Z, Afzal R. Life cycle and pathogenesis of hepatitis D virus: A review. World J Hepatol 2013;5:666-675. doi: 10.4254/wjh.v5.i12.666.

[40] Taylor JM. Virology of hepatitis D virus. Semin Liver Dis 2012;32:195-200. doi: $10.1055 / \mathrm{s}-0032-1323623$.

[41] Weiner AJ, Choo QL, Wang KS, Govindarajan S, Redeker AG, Gerin JL, et al. A single antigenomic open reading frame of the hepatitis delta virus encodes the epitope(s) of both hepatitis delta antigen polypeptides p24 delta and p27 delta. J Virol 1988;62:594-599.

[42] Chen PJ, Chang FL, Wang CJ, Lin CJ, Sung SY, Chen DS. Functional study of hepatitis delta virus large antigen in packaging and replication inhibition: role of the amino-terminal leucine zipper. J Virol 1992;66:2853-2859.

[43] Wang HW, Chen PJ, Lee CZ, Wu HL, Chen DS. Packaging of hepatitis delta virus RNA via the RNA-binding domain of hepatitis delta antigens: different roles for the small and large delta antigens. J Virol 1994;68:6363-6371.

[44] Rizzetto M, Hoyer B, Canese MG, Shih JW, Purcell RH, Gerin JL. delta Agent: association of delta antigen with hepatitis B surface antigen and RNA in serum of delta-infected chimpanzees. Proc Natl Acad Sci U S A 1980;77: 6124-6128.

[45] Rizzetto M, Canese MG, Gerin JL, London WT, Sly DL, Purcell RH. Transmission of the hepatitis $B$ virus-associated delta antigen to chimpanzees. J Infect Dis 1980;141:590-602. doi: 10.1093/infdis/141.5.590.

[46] Hadziyannis SJ, Papaioannou C, Alexopoulou A. The role of the hepatitis delta virus in acute hepatitis and in chronic liver disease in Greece. Prog Clin Biol Res 1991;364:51-62.

[47] Romeo R, Foglieni B, Casazza G, Spreafico M, Colombo M, Prati D. High serum levels of HDV RNA are predictors of cirrhosis and liver cancer in patients with chronic hepatitis delta. PLoS One 2014;9:e92062. doi: 10.1371/journal. pone.0092062.

[48] Bonino F, Negro F, Baldi M, Brunetto MR, Chiaberge E, Capalbo M, et al. The natural history of chronic delta hepatitis. Prog Clin Biol Res 1987; 234:145-152.

[49] Erhardt A, Gerlich W, Starke C, Wend U, Donner A, Sagir A, et al. Treatment of chronic hepatitis delta with pegylated interferon-alpha2b. Liver Int 2006; 26:805-810. doi: 10.1111/j.1478-3231.2006.01279.x.

[50] Gheorghe L, Iacob S, Simionov I, Vadan R, Constantinescu I, Caruntu F, et al. Weight-based dosing regimen of peg-interferon alpha-2b for chronic hepatitis delta: a multicenter Romanian trial. J Gastrointestin Liver Dis $2011 ; 20: 377-382$.

[51] Niro GA, Ciancio A, Gaeta GB, Smedile A, Marrone A, Olivero A, et al. Pegylated interferon alpha-2b as monotherapy or in combination with ribavirin in chronic hepatitis delta. Hepatology 2006;44:713-720. doi: 10.1002/hep. 21296.

[52] Kabacam G, Onder FO, Yakut M, Seven G, Karatayli SC, Karatayli E, et al. Entecavir treatment of chronic hepatitis D. Clin Infect Dis 2012;55: 645-650. doi: 10.1093/cid/cis459.

[53] Niro GA, Ciancio A, Tillman HL, Lagget M, Olivero A, Perri F, et al. Lamivudine therapy in chronic delta hepatitis: a multicentre randomized-controlled pilot study. Aliment Pharmacol Ther 2005;22:227-232. doi: 10.1111/j. 1365-2036.2005.02542.x.

[54] Wedemeyer H, Yurdaydin C, Dalekos GN, Erhardt A, Cakaloglu Y, Degertekin $\mathrm{H}$, et al. Peginterferon plus adefovir versus either drug alone for hepatitis delta. N Engl J Med 2011;364:322-331. doi: 10.1056/NEJMoa0912696.

[55] Choi SS, Rasshofer R, Roggendorf M. Inhibition of hepatitis delta virus RNA replication in primary woodchuck hepatocytes. Antiviral Res 1989;12: 213-222. doi: 10.1016/0166-3542(89)90031-4.

[56] Gunsar F, Akarca US, Ersoz G, Kobak AC, Karasu Z, Yuce G, et al. Two-year interferon therapy with or without ribavirin in chronic delta hepatitis. Antivir Ther 2005; 10:721-726. 
[57] Lutgehetmann M, Mancke LV, Volz T, Helbig M, Allweiss L, Bornscheuer $T$, et al. Humanized chimeric uPA mouse model for the study of hepatitis $B$ and D virus interactions and preclinical drug evaluation. Hepatology 2012;55: 685-694. doi: 10.1002/hep.24758.

[58] Donnelly RP, Kotenko SV. Interferon-lambda: a new addition to an old family. J Interferon Cytokine Res 2010;30:555-564. doi: 10.1089/jir. 2010.0078.

[59] Bordier BB, Ohkanda J, Liu P, Lee SY, Salazar FH, Marion PL, et al. In vivo antiviral efficacy of prenylation inhibitors against hepatitis delta virus. J Clin Invest 2003;112:407-414. doi: 10.1172/JCI200317704.

[60] Sureau C, Taylor J, Chao M, Eichberg JW, Lanford RE. Cloned hepatitis delta virus CDNA is infectious in the chimpanzee. J Virol 1989;63:4292-4297.

[61] Wu JC, Chen PJ, Kuo MY, Lee SD, Chen DS, Ting LP. Production of hepatitis delta virus and suppression of helper hepatitis $B$ virus in a human hepatoma cell line. J Virol 1991;65:1099-1104.

[62] Arribas JR, Gonzalez-Garcia J], Lorenzo A, Montero D, Ladron de Guevara C, Montes $M$, et al. Single ( $B$ or $C$ ), dual (BC or $B D$ ) and triple (BCD) viral hepatitis in HIV-infected patients in Madrid, Spain. Aids 2005; 19: 1361-1365.

[63] Colombo P, Di Blasi F, Magrin S, Fabiano C, Di Marco V, D'Amelio L, et al. Smouldering hepatitis $B$ virus replication in patients with chronic liver disease and hepatitis delta virus superinfection. J Hepatol 1991;12: 64-69. doi: 10.1016/0168-8278(91)90911-T.

[64] Lee SD, Wang JY, Wu JC, Tsai YT, Lo KJ, Lai KH, et al. Hepatitis D virus (delta agent) superinfection in an endemic area of hepatitis B infection: immunopathologic and serologic findings. Scand J Infect Dis 1987;19:173-177.

[65] Pastore G, Monno L, Santantonio T, Angarano G, Milella M, Giannelli A, et al. Hepatitis B virus clearance from serum and liver after acute hepatitis delta virus superinfection in chronic HBsAg carriers. J Med Virol 1990;31: 284-290.

[66] Sagnelli E, Felaco FM, Rapicetta M, Stroffolini T, Petruzziello A, Annella T, et al. Interaction between HDV and HBV infection in HBsAg-chronic carriers. Infection 1991;19:155-158.

[67] Jardi R, Rodriguez F, Buti M, Costa X, Cotrina M, Galimany R, et al. Role of hepatitis $B, C$, and $D$ viruses in dual and triple infection: influence of viral genotypes and hepatitis $B$ precore and basal core promoter mutations on viral replicative interference. Hepatology 2001;34:404-410. doi: 10.1053/ jhep.2001.26511.

[68] Heidrich B, Deterding K, Tillmann HL, Raupach R, Manns MP, Wedemeyer H. Virological and clinical characteristics of delta hepatitis in Central Europe. J Viral Hepat 2009;16:883-894. doi: 10.1111/j.1365-2893.2009.01144.x.

[69] Eyster ME, Sanders JC, Battegay M, Di Bisceglie AM. Suppression of hepatitis $C$ virus. (HCV) replication by hepatitis D virus (HDV) in HIVinfected hemophiliacs with chronic hepatitis B and C. Dig Dis Sci 1995; 40:1583-1588.

[70] Mathurin $P$, Thibault V, Kadidja K, Ganne-Carrie N, Moussalli ], El Younsi M, et al. Replication status and histological features of patients with triple (B, $C$ D) and dual $(B, C)$ hepatic infections. J Viral Hepat 2000; 7:15-22. doi: 10. 1046/j.1365-2893.2000.00195.x.

[71] Liaw YF, Chien RN, Chen T], Sheen IS, Chu CM. Concurrent hepatitis C virus and hepatitis delta virus superinfection in patients with chronic hepatitis $B$ virus infection. J Med Virol 1992;37:294-297.

[72] Huang CR, Lo SJ. Hepatitis D virus infection, replication and cross-talk with the hepatitis B virus. World J Gastroenterol 2014;20:14589-14597. doi: 10.3748 /wjg.v20.i40.14589.

[73] Crispim MA, Fraiji NA, Campello SC, Schriefer NA, Stefani MM, Kiesslich D. Molecular epidemiology of hepatitis $B$ and hepatitis delta viruses circulating in the Western Amazon region, North Brazil. BMC Infect Dis 2014;14:94. doi: 10.1186/1471-2334-14-94.

[74] Gomes-Gouvea MS, Soares MC, Bensabath G, de Carvalho-Mello IM, Brito EM, Souza OS, et al. Hepatitis B virus and hepatitis delta virus genotypes in outbreaks of fulminant hepatitis (Labrea black fever) in the western Brazilian Amazon region. J Gen Virol 2009;90:2638-2643. doi: 10.1099/vir.0. 013615-0.

[75] Freitas N, Abe K, Cunha C, Menne S, Gudima SO. Support of the infectivity of hepatitis delta virus particles by the envelope proteins of different genotypes of hepatitis B virus. J Virol 2014;88:6255-6267. doi: 10.1128/JVI. 00346-14.

[76] Shih $\mathrm{HH}$, Jeng KS, Syu WJ, Huang $\mathrm{YH}$, Su CW, Peng WL, et al. Hepatitis $\mathrm{B}$ surface antigen levels and sequences of natural hepatitis $B$ virus variants influence the assembly and secretion of hepatitis d virus. J Virol 2008;82: 2250-2264. doi: 10.1128/JVI.02155-07.

[77] Schaper M, Rodriguez-Frias F, Jardi R, Tabernero D, Homs M, Ruiz G, et al. Quantitative longitudinal evaluations of hepatitis delta virus RNA and hepatitis $B$ virus DNA shows a dynamic, complex replicative profile in chronic hepatitis B and D. J Hepatol 2010;52:658-664. doi: 10.1016/j.jhep.2009. 10.036 .

[78] Wedemeyer $\mathrm{H}$. Re-emerging interest in hepatitis delta: new insights into the dynamic interplay between HBV and HDV. J Hepatol 2010;52:627-629. doi: $10.1016 / j$.jhep.2010.02.001.
[79] Komla-Soukha I, Sureau C. A tryptophan-rich motif in the carboxyl terminus of the small envelope protein of hepatitis $B$ virus is central to the assembly of hepatitis delta virus particles. J Virol 2006;80:4648-4655. doi: 10.1128/ JVI.80.10.4648-4655.2006.

[80] Jaroszewicz J, Calle Serrano B, Wursthorn K, Deterding K, Schlue J, Raupach $\mathrm{R}$, et al. Hepatitis B surface antigen (HBsAg) levels in the natural history of hepatitis B virus (HBV)-infection: a European perspective. J Hepatol 2010; 52:514-522. doi: 10.1016/j.jhep.2010.01.014

[81] European Association For The Study Of The Liver. EASL Clinical Practice Guidelines: management of chronic hepatitis B. J Hepatol 2009;50: 227-242. doi: 10.1016/j.jhep.2008.10.001.

[82] Lee JH, Kim SJ, Ahn SH, Lee J, Park Y, Kim HS. Correlation between quantitative serum HBsAg and HBV DNA test in Korean patients who showed high level of HBsAg. J Clin Pathol 2010;63:1027-1031. doi: 10.1136/jcp. 2010. 078832.

[83] Volz T, Lutgehetmann M, Wachtler P, Jacob A, Quaas A, Murray JM, et al. Impaired Intrahepatic Hepatitis B Virus Productivity Contributes to Low Viremia in Most HBeAg-Negative Patients. Gastroenterology 2007;133: 843-852. doi: 10.1053/j.gastro.2007.06.057.

[84] Janssen HL, Sonneveld MJ, Brunetto MR. Quantification of serum hepatitis B surface antigen: is it useful for the management of chronic hepatitis $B$ ? Gut 2012;61:641-645. doi: 10.1136/gutjnl-2011-301096.

[85] Sheldon J, Ramos B, Toro C, Rios P, Martinez-Alarcon J, Bottecchia M, et al. Does treatment of hepatitis $B$ virus (HBV) infection reduce hepatitis delta virus (HDV) replication in HIV-HBV-HDV-coinfected patients? Antivir Ther 2008;13:97-102.

[86] Kuo MY, Chao M, Taylor J. Initiation of replication of the human hepatitis delta virus genome from cloned DNA: role of delta antigen. J Virol 1989; 63:1945-1950.

[87] Wang CJ, Chen PJ, Wu JC, Patel D, Chen DS. Small-form hepatitis B surface antigen is sufficient to help in the assembly of hepatitis delta virus-like particles. J Virol 1991;65:6630-6636.

[88] Sureau C, Guerra B, Lanford RE. Role of the large hepatitis B virus envelope protein in infectivity of the hepatitis delta virion. J Virol 1993;67:366-372.

[89] Gowans EJ, Baroudy BM, Negro F, Ponzetto A, Purcell RH, Gerin JL. Evidence for replication of hepatitis delta virus RNA in hepatocyte nuclei after in vivo infection. Virology 1988;167:274-278.

[90] Huang WH, Chen CW, Wu HL, Chen PJ. Post-translational modification of delta antigen of hepatitis D virus. Curr Top Microbiol Immunol 2006;307: 91-112.

[91] Tan KP, Shih KN, Lo SJ. Ser-123 of the large antigen of hepatitis delta virus modulates its cellular localization to the nucleolus, SC-35 speckles or the cytoplasm. J Gen Virol 2004;85:1685-1694.

[92] Hourioux C, Sureau C, Poisson F, Brand D, Goudeau A, Roingeard P. Interaction between hepatitis delta virus-encoded proteins and hepatitis $B$ virus envelope protein domains. J Gen Virol 1998;79:1115-1119.

[93] Hwang SB, Lai MM. Isoprenylation mediates direct protein-protein interactions between hepatitis large delta antigen and hepatitis B virus surface antigen. J Virol 1993;67:7659-7662.

[94] Huang IC, Chien CY, Huang CR, Lo SJ. Induction of hepatitis D virus large antigen translocation to the cytoplasm by hepatitis $\mathrm{B}$ virus surface antigens correlates with endoplasmic reticulum stress and NF-kappaB activation. J Gen Virol 2006;87:1715-1723. doi: 10.1099/vir.0.81718-0.

[95] Goto T, Kato N, Yoshida H, Otsuka M, Moriyama M, Shiratori Y, et al. Synergistic activation of the serum response element-dependent pathway by hepatitis $B$ virus $x$ protein and large-isoform hepatitis delta antigen. J Infect Dis 2003;187:820-828.

[96] Modahl LE, Lai MM. The large delta antigen of hepatitis delta virus potently inhibits genomic but not antigenomic RNA synthesis: a mechanism enabling initiation of viral replication. J Virol 2000;74:7375-7380. doi: $10.1128 / \mathrm{JVI}$ 74.16.7375-7380.2000.

[97] Williams V, Brichler S, Radjef N, Lebon P, Goffard A, Hober D, et al. Hepatitis delta virus proteins repress hepatitis $B$ virus enhancers and activate the alpha/beta interferon-inducible MxA gene. J Gen Virol 2009;90:2759-2767. doi: 10.1099/vir.0.011239-0.

[98] Dastgerdi ES, Herbers U, Tacke F. Molecular and clinical aspects of hepatitis D virus infections. World J Virol 2012;1:71-78. doi: 10.5501/wjv.v1.i3.71.

[99] Hsu SC, Syu WJ, Sheen IJ, Liu HT, Jeng KS, Wu JC. Varied assembly and RNA editing efficiencies between genotypes I and II hepatitis D virus and their implications. Hepatology 2002;35:665-672. doi: 10.1053/jhep. 2002.31777.

[100] Oliveri F, Brunetto MR, Baldi M, Piantino P, Ponzetto A, Forzani B, et al. Hepatitis delta virus (HDV) infection and hepatocellular carcinoma (HCC). Prog Clin Biol Res 1991;364:217-222.

[101] Wei Y, Ganem D. Activation of heterologous gene expression by the large isoform of hepatitis delta antigen. J Virol 1998;72:2089-2096.

[102] Cole SM, Gowans EJ, Macnaughton TB, Hall PD, Burrell CJ. Direct evidence for cytotoxicity associated with expression of hepatitis delta virus antigen. Hepatology $1991 ; 13: 845-851$. 
[103] Govindarajan S, Fields HA, Humphrey CD, Margolis HS. Pathologic and ultrastructural changes of acute and chronic delta hepatitis in an experimentally infected chimpanzee. Am J Pathol 1986;122:315-322.

[104] Popper H, Thung SN, Gerber MA, Hadler SC, de Monzon M, Ponzetto A, et al. Histologic studies of severe delta agent infection in Venezuelan Indians. Hepatology 1983;3:906-912.

[105] Wedemeyer H, Manns MP. Epidemiology, pathogenesis and management of hepatitis D: update and challenges ahead. Nat Rev Gastroenterol Hepatol 2010;7:31-40. doi: 10.1038/nrgastro.2009.205.

[106] Wieland SF, Spangenberg HC, Thimme R, Purcell RH, Chisari FV. Expansion and contraction of the hepatitis $B$ virus transcriptional template in infected chimpanzees. Proc Natl Acad Sci U S A 2004;101:2129-2134. doi: 10.1073/pnas.0308478100.

[107] Giersch K, Allweiss L, Volz T, Helbig M, Bierwolf J, Lohse AW, et al. Hepatitis Delta co-infection in humanized mice leads to pronounced induction of innate immune responses in comparison to HBV mono-infection. J Hepatol 2015;63:346-353. doi: 10.1016/j.jhep.2015.03.011.

[108] Dunn C, Peppa D, Khanna P, Nebbia G, Jones M, Brendish N, et al. Temporal analysis of early immune responses in patients with acute hepatitis $B$ virus infection. Gastroenterology 2009;137:1289-1300. doi: 10.1053/j.gastro. 2009.06.054.

[109] Lang T, Lo C, Skinner N, Locarnini S, Visvanathan K, Mansell A. The hepatitis $\mathrm{B}$ e antigen ( $\mathrm{HBeAg}$ ) targets and suppresses activation of the toll-like receptor signaling pathway. J Hepatol 2011;55:762-769. doi: 10.1016/j. jhep.2010.12.042.

[110] Jiang M, Broering R, Trippler M, Poggenpohl L, Fiedler M, Gerken G, et al. Toll-like receptor-mediated immune responses are attenuated in the presence of high levels of hepatitis B virus surface antigen. J Viral Hepat 2014; 21:860-872. doi: 10.1111/jvh.12216.

[111] Momeni M, Zainodini N, Bidaki R, Hassanshahi G, Daneshvar H, Khaleghinia M, et al. Decreased expression of toll like receptor signaling molecules in chronic HBV infected patients. Hum Immunol 2014;75:15-19. doi: 10.1016/j. humimm.2013.09.015.

[112] Wu M, Xu Y, Lin S, Zhang X, Xiang L, Yuan Z. Hepatitis B virus polymerase inhibits the interferon-inducible MyD88 promoter by blocking nuclear translocation of Stat1. J Gen Virol 2007;88:3260-3269. doi: 10.1099/vir.0. 82959-0.

[113] Lutgehetmann M, Bornscheuer T, Volz T, Allweiss L, Bockmann JH, Pollok $J M$, et al. Hepatitis B virus limits response of human hepatocytes to interferon-alpha in chimeric mice. Gastroenterology 2011;140:2074-2083. doi: $10.1053 /$ j.gastro.2011.02.057
[114] Christen V, Duong F, Bernsmeier C, Sun D, Nassal M, Heim MH. Inhibition of alpha interferon signaling by hepatitis B virus. J Virol 2007;81:159-165. doi: 10.1128/JVI.01292-06.

[115] Park IY, Sohn BH, Yu E, Suh DJ, Chung YH, Lee JH, et al. Aberrant epigenetic modifications in hepatocarcinogenesis induced by hepatitis $B$ virus $X$ protein. Gastroenterology 2007;132:1476-1494. doi: 10.1053/j.gastro. 2007.01.034

[116] Vivekanandan $P$, Daniel HD, Kannangai R, Martinez-Murillo F, Torbenson M. Hepatitis $B$ virus replication induces methylation of both host and viral DNA. J Virol 2010;84:4321-4329. doi: 10.1128/JVI.02280-09.

[117] Wei C, Ni C, Song T, Liu Y, Yang X, Zheng Z, et al. The hepatitis B virus X protein disrupts innate immunity by downregulating mitochondrial antiviral signaling protein. J Immunol 2010;185:1158-1168. doi: 10.4049/jimmunol. 0903874.

[118] Hare D, Mossman KL. Novel paradigms of innate immune sensing of viral infections. Cytokine 2013:63:219-224 doi: 10.1016/j.cyto.2013.06.001.

[119] Bertoletti A, Ferrari C. Innate and adaptive immune responses in chronic hepatitis $B$ virus infections: towards restoration of immune control of viral infection. Postgrad Med J 2012;89:294-304. doi: 10.1136/postgradmedj2011-301073rep.

[120] Actis GC, Maran E, Rosina F, Saracco G, Rocca G, Rizzetto M, et al. Natural killer response to exogenous interferon in delta hepatitis: boost or depression defined within the first week of therapy. Digestion 1987;37:51-58.

[121] Lunemann S, Malone DF, Grabowski J, Port K, Beziat V, Bremer B, et al. Effects of HDV infection and pegylated interferon alpha treatment on the natural killer cell compartment in chronically infected individuals. Gut 2015;64:469-482. doi: 10.1136/gutjnl-2014-306767.

[122] Park H, Serti E, Eke O, Muchmore B, Prokunina-Olsson L, Capone S, et al. IL-29 is the dominant type III interferon produced by hepatocytes during acute hepatitis C virus infection. Hepatology 2012;56:2060-2070. doi: 10.1002/hep.25897.

[123] Pugnale P, Pazienza V, Guilloux K, Negro F. Hepatitis delta virus inhibits alpha interferon signaling. Hepatology 2009;49:398-406. doi: 10.1002/ hep. 22654.

[124] Aslan N, Yurdaydin C, Bozkaya H, Baglan P, Bozdayi AM, Tillmann HL, et al. Analysis and function of delta-hepatitis virus-specific cellular immune responses. J Hepatol 2003;38:15-16.

[125] Aslan N, Yurdaydin C, Wiegand J, Greten T, Ciner A, Meyer MF, et al. Cytotoxic CD4 T cells in viral hepatitis. J Viral Hepat 2006;13:505-514. doi: $10.1111 / \mathrm{j} .1365-2893.2006 .00723 . x$.

[126] Huang $\mathrm{YH}, \mathrm{Tao} \mathrm{MH}, \mathrm{Hu} C \mathrm{CP}$, Syu WJ, Wu JC. Identification of novel HLAA*0201-restricted CD8+ T-cell epitopes on hepatitis delta virus. J Gen Virol 2004;85:3089-3098. doi: 10.1099/vir.0.80183-0. 